\title{
Impact of carprofen administration on stress and nociception responses of calves to cautery dehorning ${ }^{1}$
}

\author{
M. L. Stock, $* \dagger$ L. A. Barth, + N. K. Van Engen, $\dagger$ S. T. Millman, $* \dagger$ R. Gehring, $\S$ \\ C. Wang, $\dagger$ E. A. Voris,\# L. W. Wulf,\# Léa Labeur, $\uparrow$ W. H. Hsu, * and J. F. Coetzee $\#^{2}$ \\ *Department of Biomedical Sciences, $\uparrow$ Veterinary Diagnostic and Production Animal Medicine, \\ $\$$ Veterinary Clinical Sciences, and \#Pharmacology Analytical Support Team (PhAST), College of \\ Veterinary Medicine, Iowa State University, Ames 50010; and §Department of Anatomy and \\ Physiology, College of Veterinary Medicine, Kansas State University, Manhattan 66506
}

\begin{abstract}
The objective of this study was to investigate the effects of carprofen administered immediately before cautery dehorning on nociception and stress. Forty Holstein calves aged approximately 6 to 8 wk old were either placebo treated and sham dehorned $(n=10)$ or cautery dehorned following administration of carprofen $(1.4 \mathrm{mg} / \mathrm{kg})$ subcutaneously $(n=10)$ or orally $(n=10)$ or a subcutaneous and oral placebo $(n=10)$ in a randomized, controlled trial. All animals were given a cornual nerve block using lidocaine before dehorning. Response variables including mechanical nociception threshold, ocular temperature, heart rate, and respiratory rate were measured before and following cautery dehorning for $96 \mathrm{~h}$. Blood samples were also collected over 96 $\mathrm{h}$ following dehorning and analyzed for plasma cortisol and substance $\mathrm{P}$ concentrations by RIA. Plasma carprofen concentration and ex vivo $\mathrm{PGE}_{2}$ concentrations were also determined for this time period. Average daily gain was calculated for $7 \mathrm{~d}$ after
\end{abstract}

dehorning. Data were analyzed using a linear mixed effects model with repeated measures, controlling for baseline values by their inclusion as a covariate in addition to planned contrasts. Dehorning was associated with decreased nociception thresholds throughout the study and a stress response immediately after dehorning, following the loss of local anesthesia, and $48 \mathrm{~h}$ after dehorning compared with sham-dehorned calves. Carprofen was well absorbed after administration and reached concentrations that inhibited ex vivo $\mathrm{PGE}_{2}$ concentrations for $72 \mathrm{~h}$ (subcutaneous) and $96 \mathrm{~h}$ (oral) compared with placebo-treated calves $(P<0.05)$. Carprofen-treated calves tended to be less sensitive $(P=0.097)$ to nociceptive threshold tests. Overall, at the dosing regimen studied, the effect of carprofen on sensitivity and stress following cautery dehorning was minimal. Consideration of route of administration and dose determination studies may be warranted.

Key words: animal welfare, dehorning, nociception, nonsteroidal anti-inflammatory drugs, stress

\section{INTRODUCTION}

\footnotetext{
${ }^{1}$ Supported by the Pharmacology Analytical Support Team (PhAST) in the College of Veterinary Medicine at Iowa State University. The authors thank the following individuals, who provided invaluable support to the project: Stephen Ball, Rebecca Parsons, Jackie Peterson, and Kelly Pertzborn.

${ }^{2}$ Corresponding author: hcoetzee@iastate.edu

Received July 8, 2015.

Accepted October 27, 2015.
}

The pain and stress associated with dehorning has been evaluated using changes to physiology, behavior, and the neuroendocrine system (Stafford and Mellor, 2011). Analysis of affective states such as pain and distress are often achieved through the measurement of indirect measures such as changes in the hypothalamic-pituitary-adrenal axis (McMeekan et al., 1998), autonomic nervous system response (Stewart 
et al., 2008), and behavior (Faulkner and Weary, 2000). Despite these previously reported changes following a noxious event, there are currently no approved analgesics for cattle in the United States (Coetzee, 2013a).

Several pain mitigating strategies have been evaluated. Through reductions in cortisol, a multimodal approach to analgesia including the use of local anesthesia (McMeekan et al., 1998), nonsteroidal antiinflammatory drugs (NSAID; Huber et al., 2013), or sedatives (Stilwell et al., 2010) may provide optimal pain relief (Coetzee, 2013b). Furthermore, in addition to the fundamental use of local anesthesia in cautery dehorning, analgesics with persistent activity may be beneficial (Heinrich et al., 2010).

Carprofen is an NSAID with a prolonged half-life in cattle that is administered as a racemic ( $\mathrm{RS} \pm$ ) mixture (Brentnall et al., 2013). Currently, it is approved in countries in Europe as an adjunctive treatment for inflammation associated with pneumonia in young calves. Carprofen has demonstrated both cyclooxygenase (COX)-dependent (Miciletta et al., 2014) and COX-independent mechanisms including attenuating IL-6, a proinflammatory cytokine in equine synoviocytes and chondrocytes (Armstrong and Lees, 2002). As IL-6 has been reported to mediate the pain associated with burns in rodents, carprofen may provide effective pain management following cautery dehorning (Summer et al., 2008).

The objective of our study is to investigate the effect of perioperatively administered carprofen on nociception and stress following cautery dehorning.

\section{MATERIALS AND METHODS}

\section{Animals and Housing}

Forty Holstein calves (18 castrated males and 22 females) with a mean age of $50.9 \mathrm{~d}$ (SD 5.3) and mean weight of $63.8 \mathrm{~kg}$ (SD 8.7) at dehorning were included in this study. Calves were obtained from the Iowa State University Dairy (Ames, IA) and weaned at approximately 4 wk of age. Male calves were band castrated within the first week of life according to onfarm practices. The scrotum of 1 animal was present at the time of enrollment but was included in the study due to a lack of swelling or inflammation observed and a healthy physical examination. The castration sites for all other animals had healed. All calves were determined healthy by a physical examination by a veterinarian. This study protocol was approved by the Institutional Animal Care and Use Committee at Iowa State University (log number 5-13-7566-B).

Calves were housed in a naturally ventilated group housing facility on the Iowa State University Dairy. A total of 5 groups of 8 animals were moved from individual 3-sided pens into group housing at least $6 \mathrm{~d}$ before dehorning for environmental and social acclimatization. Group pens (3.7 by $6.4 \mathrm{~m}$ ) were bedded with straw added daily. Water and grain, consisting of primarily pelleted corn, oats, molasses protein/vita$\mathrm{min} /$ mineral supplement, and monensin, were fed to the calves ad libitum for the duration of the trial (Table 1). The study was conducted in July and August.

Animals were monitored twice daily for health observations. Animals appearing depressed or lethargic were examined by a veterinarian and monitored or treated accordingly. Veterinarian diagnosed respiratory disease was diagnosed based on persistent elevated rectal temperature $\left(>39.7^{\circ} \mathrm{C}\right)$, spontaneous cough, and ocular and/or nasal discharge. Respiratory disease was treated using tulathromycin $(2.5 \mathrm{mg} / \mathrm{kg}$; Draxxin; Pfizer Inc., New York, NY) with resolution of clinical signs following treatment. Overall, 1 animal was treated in the non-dehorned, placebo treated (SHAM) group, 2 animals were treated in both the oral carprofen, dehorned (PO) and placebo-treated dehorned (PLCBO) groups, and 3 animals were treated in the subcutaneous carprofen, dehorned (SQ) group throughout the length of the study. Treatment of respiratory disease did not include administration of an NSAID. Calves did not require further treatment for any other disease process.

\section{Study Design}

A randomized controlled trial design was used for this investigation. Study animals were randomly assigned to be either placebo treated and SHAM dehorned (SHAM; $n=10$ ) or cautery dehorned following administration of carprofen $(1.4 \mathrm{mg} / \mathrm{kg}$ ) orally (PO; $n$ $=10$ ) or subcutaneously (SQ; $n=10$ ) or a subcutaneous and oral placebo (PLCBO; $n=10$; Fig. 1). All animals were administered an oral bolus and an injection. Animals not enrolled in the oral carprofen group were administered an oral lactose placebo and those animals not enrolled in the SQ group were given an injection of sterile saline. Randomization of group assignments

Table 1. As-fed (\%) components of the grain diet provided to calves throughout the study

\begin{tabular}{lc}
\hline \hline Component & As fed, $\%$ \\
\hline Corn & 50 \\
Oats & 5 \\
Commercial supplement ${ }^{1}$ (38\% protein) & 30 \\
Commercial supplement (34\% protein) & 10 \\
Liquid molasses & 5 \\
\hline
\end{tabular}

${ }^{1}$ Contains monensin. 


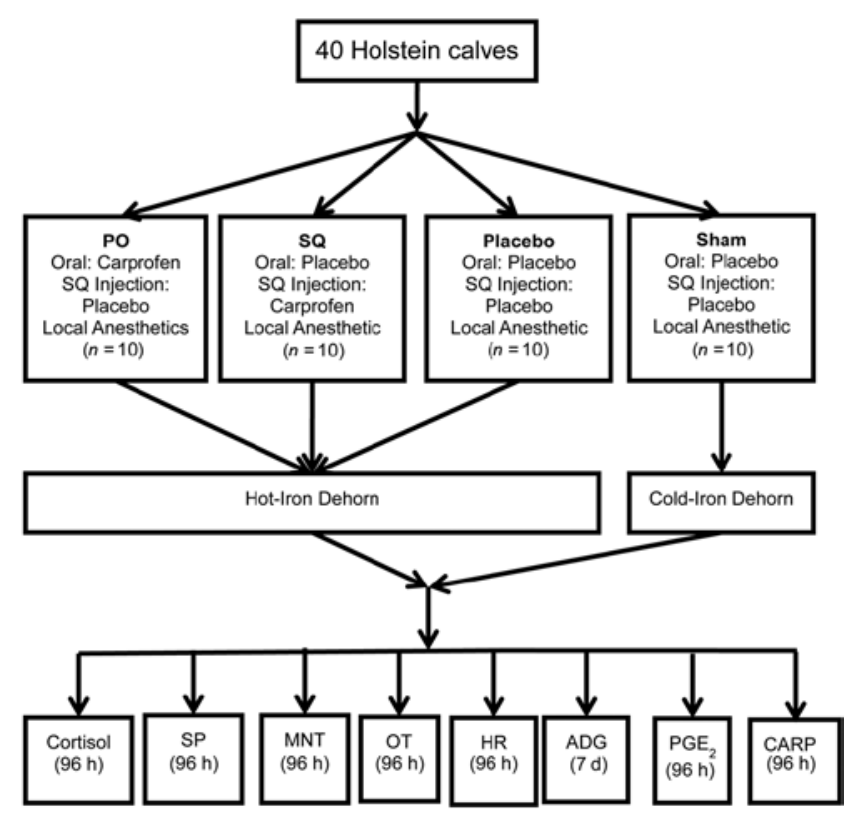

Figure 1. Flow chart outlining the timing of the study events. Calves were dehorned and monitored for cortisol, substance P (SP), mechanical nociception threshold (MNT), ocular temperature (OT), heart rate (HR), $\mathrm{ADG}$, ex vivo $\mathrm{PGE}_{2}$, and carprofen (CARP) concentration. The times in parentheses represent the duration of data collection for each variable. $\mathrm{PO}$ $=$ oral carprofen, dehorned group; $\mathrm{SQ}=$ subcutaneous carprofen, dehorned group.

was accomplished using a computer generated random number (Microsoft Excel 2011; Microsoft Corporation, Redmond, WA) with animals blocked by weight within sex. Following randomization and group assignment, calves were enrolled in 1 of 4 treatment groups $(n=$ 10) containing equal number of animals. Five phases of 8 calves per phase were used during a 6 -wk period of time. Two animals from each treatment group were represented in each phase $(n=2$ calves/treatment for each phase) and animals in each phase were housed in equivalent pens.

A jugular catheter was placed for the purpose of blood sample collection. Placement of the jugular catheter occurred approximately $12 \mathrm{~h}$ before the start of the investigation. Calves were restrained by a handler during the process of catheter placement. The area over the jugular vein was clipped and surgically prepared with alternating scrubs of $70 \%$ isopropyl alcohol and povidone iodine. The catheter site was infiltrated with 2\% lidocaine injection, $1 \mathrm{~mL}$ subcutaneously (Phoenix; Sparhawk Laboratories, Inc., Lenexa, KS). Using sterile technique, an 18-gauge by $55-\mathrm{mm}$ intravenous catheter (SURFLO; Terumo Medical Corp., Somerset, NJ) with injection plug (Hospira Inc., Lake Forest, IL) was inserted into the vein and sutured to the skin using number 3 nylon suture (Ethilon; Ethicon, San Lorenzo, PR). Catheter patency was maintained by flushing with $3 \mathrm{~mL}$ of a heparin saline solution containing 3 United States Pharmacopeia units heparin sodium $/ \mathrm{mL}$ saline (Heparin Sodium Injection; Baxter Healthcare, Deerfield, IL). The catheter port was disinfected with an alcohol swab before sample collection.

Study animals $(n=10)$ were administered SQ carprofen $(1.4 \mathrm{mg} / \mathrm{kg}$; Rimadyl Injectable, $50 \mathrm{mg} / \mathrm{mL}$; new animal drug application [NADA] number 141-199; Pfizer Inc.) under the skin in the cervical muscular region. The dose was rounded to the nearest tenth milliliter and administered in a 3-mL syringe. Calves enrolled in the other groups not administered SQ carprofen (PO, PLCBO, and SHAM) were given an equivalent amount of $0.9 \%$ saline subcutaneously in the same manner previously described.

Oral carprofen $(1.4 \mathrm{mg} / \mathrm{kg})$ administration was completed using tablets of 2 different concentrations to provide the most accurate targeted dose. Either 100-mg tablets (Novox Caplets, abbreviated NADA [ANADA] number 200-498; Vedco, Inc., St. Joseph, $\mathrm{MO}$ ) or 75-mg tablets (Novox Caplets, ANADA number 200-498; Vedco, Inc.) were provided to calves in a small gelatin capsule (Torpac, Inc., Fairfield, NJ) administered using an oral balling gun. Using the 2 different formulations, the dose was rounded to the nearest tablet of the weight determined $24 \mathrm{~h}$ before administration. Using these 2-tablet formulations, the actual mean dose of $1.40 \mathrm{mg} / \mathrm{kg}$ (range $1.13-1.63 \mathrm{mg}$ / $\mathrm{kg}$ ) was administered to the calves as an oral bolus. Animals not given an oral carprofen (SQ, PLCBO, and SHAM) were identically administered a placebo (lactose powder) encapsulated in the same gelatin bolus.

\section{Dehorning}

Dehorning was performed in 10-min intervals. Calves were restrained during dehorning using a modified calf restraining device (Easy B-Z Portable Calf Restraint; Nasco, Fort Atkinson, WI). Cautery dehorning was initiated $10 \mathrm{~min}$ following administration of the oral bolus, subcutaneous injection, and local anesthetic. All calves were given a local anesthetic before actual or sham cautery dehorning. Desensitization of the cornual tissue was provided via a cornual nerve block using 2\% lidocaine (VetOne, Boise, ID; $5 \mathrm{~mL} /$ site) as described by Stock et al (2013). Effective local anesthesia of the cornual tissue was confirmed using a lack of behavior reactions (e.g., ear flicks, head shaking, strong escape behavior) to a needle prick 5 min after administration of the cornual nerve block. Calves were cautery dehorning by placement of a preheated electrical hot iron (approximately $600^{\circ} \mathrm{C}$; Dehorner X-50; Rhinehart Development Corporation, Spencerville, IN) on the horn tissue for approximately 15 to $20 \mathrm{~s}$ until a circumferential copper-colored ring surrounding the horn bud was formed after in- 
vestigators confirmed adequate desensitization. A duplicate, nonheated electric dehorner (Dehorner X-50; Rhinehart Development Corporation) was identically used for SHAM animals. Each group of 8 study animals was dehorned by the same person to minimize variation within the phase.

The dehorning sites were monitored daily for signs of discharge or infection, in addition to an assessment of attitude, posture, appetite, lying time, and perioperative swelling.

\section{Blood Sample Collection}

Animals were restrained during blood collection by trained handlers. Before blood collection, approximately $5 \mathrm{~mL}$ of blood was aspirated in the syringe and returned through the catheter 3 times to remove the heparin flush from the catheter. Baseline samples were obtained approximately $1 \mathrm{~h}$ before drug administration. Blood samples were collected for animals given carprofen or placebo via the catheter at $0.5,0.75,1,2$, $4,6,8,10,12,24,48,72$, and $96 \mathrm{~h}$ (-10 min) following dehorning. Samples were immediately transferred to a blood collection tube with either sodium heparin or EDTA (Vacutainer; BD Diagnostics, Franklin Lakes, NJ) and stored in a cooler with ice packs before processing. Blood samples were centrifuged for $15 \mathrm{~min}$ at $1,500 \times \mathrm{g}$ at ambient temperature. Collected plasma was placed in cryovials and frozen at $-80^{\circ} \mathrm{C}$ until analysis.

Calves were loosely restrained using the same head restraint as previously described approximately 5 min before nociception threshold detection via pressure algometry and infrared thermography at 4, 8, 12, $24,48,72$, and $96 \mathrm{~h}$ after dehorning. Blood collection would occur before calves were placed in the head restraint. After this brief period of acclimatization in the restraint device, infrared images were obtained. Following infrared thermography imaging, calves were blindfolded for pressure algometry nociception threshold testing to avoid conditioned withdrawal reflex based on visual cues. Baseline samples for heart rate, respiratory rate, ocular temperature, and mechanical nociception threshold (MNT) were obtained $14 \pm$ $2 \mathrm{~h}$ before the initiation of the study.

\section{Ocular Temperature}

A thermography camera (FLIR SC 660; FLIR Systems AB, Boston, MA) with a thermal sensitivity of $0.05^{\circ} \mathrm{C}, 320 \times 240$ pixel display, and precision $>98 \%$ was used to quantify changes in ocular temperature similarly described in Stock et al. (2013). The camera was internally calibrated to ambient tempera- ture before image collection; however, additional minute adjustments to ambient temperature and humidity were used during software processing. Images were obtained from the left side of the calf, at an angle of approximately $45^{\circ}$ and a distance of $0.5 \mathrm{~m}$ from the eye. Maximum temperature $\left({ }^{\circ} \mathrm{C}\right)$ within a circumferential area of the eye including the medial posterior palpebral border of the lower eyelid and the lacrimal caruncle was obtained as previously described (Stewart el al., 2008). Images were analyzed using FLIR Tools (version 4.1; FLIR Systems Inc., Boston, MA) following collection. At each time point, 3 images were obtained and the minimum temperature recorded was used for statistical analysis.

\section{Mechanical Nociception Threshold}

The MNT, as defined by a maximum force that induces a withdrawal response, was determined at 4,8 , $12,24,48,72$, and $96 \mathrm{~h}$ after dehorning as described in Tapper et al. (2011) and Stock et al. (2013). Briefly, using a hand-held pressure algometer (Wagner Force Ten FDX 25 Compact Digital Force Gage; Wagner Instruments, Riverside, CT), a force was applied perpendicular at a rate of approximately $1 \mathrm{~kg}$ of force per second at 2 locations (lateral and caudal) adjacent to the horn bud. The $1-\mathrm{cm}^{2}$ rubber tip of the algometer was placed immediately adjacent to cauterized skin. Additionally, a third control location between the eyes on the frontal bone was used to evaluate the MNT of an area that was not adjacent to cauterized skin. A withdrawal response was indicated by an overt movement away from the applied pressure algometer, which remained observable in the loose head restraint. The obtained pressure value was recorded by a second researcher before observation from the investigator applying the pressure. A maximum value of $10 \mathrm{kgf}$ was determined a priori. Calves were blindfolded before the MNT test to avoid a response associated with visual cues. Both the order of locations tested and the side of the calf the researcher stood on was randomized between each calf. Locations were tested 3 times in sequential order and the value was averaged for statistical analysis.

\section{Heart and Respiratory Rate}

Heart and respiratory rates were obtained before placement within the restraining device. Respiratory rates were obtained by a recorder outside of the group pen and heart rates were determined following a brief period of acclimatization of the recorder in the group pen. In this way, the restraining device would not influence respiratory and heart rates. 
Heart and respiratory rates were evaluated via auscultation at 3.5, 7.5, 11.5, 23.5, 47.5, 71.5, and 95.5 $\mathrm{h}( \pm 0.5)$. The bell of a stethoscope (Littmann, Master Classic II; 3M, St. Paul, MN) was placed between the third and fifth intercostal space and beats were counted over a $15 \mathrm{~s}$ period. The value obtained was used to calculate beats per minute. Respiratory rates were calculated using the number of breaths observed per $15 \mathrm{~s}$ and multiplying by 4 .

\section{Average Daily Gain}

Animals were weighed using a Brecknell digital scale (PS500-36S; Avery Weigh-Tronix, Fairmont, $\mathrm{MN}$ ). Average daily gain was calculated using weights obtained approximately $24 \mathrm{~h}$ before the carprofen administration $(\mathrm{d}-1)$ and $7 \mathrm{~d}$ following dehorning $(\mathrm{d} 7)$. The scale was calibrated with weights of a known mass immediately before obtaining the weight of a calf.

\section{Cortisol}

Plasma cortisol concentrations were determined using a commercial RIA kit (Coat-A-Count Cortisol; Siemens Medical Solutions Diagnostics [formally Diagnostic Products Corp.], Los Angeles, CA) previously used for bovine plasma collected in heparin at 0.5 , $0.75,1,2,4,6,8,10,12,24,48,72$, and $96 \mathrm{~h}$ (-10 min) after dehorning (Stilwell et al., 2008a). Samples were assayed in duplicate with the reported concentration equaling the average cortisol concentration between duplicates. The average intra- and interassay $\mathrm{CV}$ were 8.2 and $7.8 \%$, respectively. The area under the effect curve (AUEC) was calculated using the linear trapezoidal method as previously described (Glynn et al., 2013).

\section{Substance P}

Substance P (SP) concentrations were analyzed as described by Van Engen et al. (2014) using nonextracted plasma collected in EDTA at $0.5,0.75,1,2,4$, $6,8,10,12,24,48,72$, and $96 \mathrm{~h}$ (-10 min) after dehorning. Samples were assayed in duplicate with the reported concentration equaling the average SP concentration between duplicates. The $\mathrm{CV}$ for intra-assay variability was at $8.6 \%$ and the interassay variability was calculated at $8.4 \%$. The AUEC was calculated using the linear trapezoidal method.

\section{Prostaglandin $E_{2}$}

Ex vivo $\mathrm{PGE}_{2}$ concentrations were determined as described by Fraccaro et al. (2013). Blood collected from calves was placed into sterile vacuum tubes containing heparin at 2, 6, 12, 24, 48, 72, $96 \mathrm{~h}$. Lipopolysaccharide (LPS) obtained from Escherichia coli 0111:B4 (SigmaAldrich Corp., St. Louis, MO) in PBS was added at 10 $\mu \mathrm{g} / \mathrm{mL}$ to the heparinized whole blood and incubated for $24 \mathrm{~h}$ at $37^{\circ} \mathrm{C}$. Baseline samples were incubated with and without LPS before administration of carprofen. The same volume of PBS was added to the negative control baseline samples. At the end of incubation, all samples were centrifuged at $400 \times g$ for $10 \mathrm{~min}$ at ambient temperature to obtain plasma. Methanol was added to plasma in a 1:5 plasma to methanol dilution, facilitating protein precipitation. Following centrifugation at $3,000 \times \mathrm{g}$ for $10 \mathrm{~min}$ at ambient temperature, the supernatant was collected and stored at $-80^{\circ} \mathrm{C}$. A commercial $\mathrm{PGE}_{2}$ ELISA kit (Cayman Chemical, Ann Arbor, MI) previously described using methanol precipitated bovine plasma was used for determination of $\mathrm{PGE}_{2}$ concentration (Donalisio et al., 2013; Fraccaro et al., 2013). Samples were assayed in duplicate with the concentration equaling the average $\mathrm{PGE}_{2}$ concentration. Prostaglandin $\mathrm{E}_{2}$ was statistically analyzed and reported as a percent inhibition, which was calculated using the formula

$$
\begin{aligned}
& \left(\mathrm{PGE}_{2}-\text { baseline } \mathrm{PGE}_{2} / \text { baseline } \mathrm{PGE}_{2}\right) \times 100 \\
& =\text { percent inhibition, }
\end{aligned}
$$

in which $\mathrm{PGE}_{2}$ is the concentration of $\mathrm{PGE}_{2}$ after dehorning at each sample time point and baseline $\mathrm{PGE}_{2}$ was obtained before administration of carprofen. The CV for intra-assay variability was at $9.8 \%$ and the interassay variability was calculated at $14.6 \%$. One animal from each of the PLCBO and SQ treatment groups were removed from analysis due to laboratory error.

\section{Carprofen Plasma Concentration}

Plasma concentrations of carprofen ( $\mathrm{R}$ and $\mathrm{S}$ enantiomers) were determined using HPLC (Agilent 1100 Pump and Autosampler; Agilent Technologies, Santa Clara, CA) coupled with ion trap mass spectrometry detection (LTQ; Thermo Scientific, San Jose, CA). Plasma samples, plasma spikes, and blanks, 100 $\mu \mathrm{L}$, were mixed with $400 \mu \mathrm{L}$ of acetonitrile to precipitate plasma proteins. Diclofenac $(10 \mu \mathrm{L}$ of $5 \mathrm{ng} / \mu \mathrm{L})$ was added as an internal standard to all samples. The samples were vortexed for $5 \mathrm{~s}$ and centrifuged for 20 $\min$ at $2,000 \times g$ at ambient temperature to sediment the protein pellet. The supernatant was poured off into dry down tubes and evaporated at $50^{\circ} \mathrm{C}$ with a flow of nitrogen in a Turbovap (Biotage, Charlotte, NC). The contents were reconstituted with $150 \mu \mathrm{L}$ of $25 \%$ acetonitrile in water. The samples were transferred to an autosampler vials fitted with a glass insert and centri- 
fuged at $2,000 \times g$ for $10 \mathrm{~min}$ at ambient temperature before analysis.

For liquid chromatography-mass spectrometry analysis, the injection volume was set to $15 \mu \mathrm{L}$. The mobile phases consisted of $\mathrm{A}, 0.1 \%$ formic acid in water, and $\mathrm{B}, 0.1 \%$ formic acid in acetonitrile, at a flow rate of $0.225 \mathrm{~mL} / \mathrm{min}$. A solvent gradient beginning at $40 \%$ B with a linear gradient to $60 \%$ B in 5 min was used for analysis. Separation was achieved with a LUX Cellulose- 1 chiral column, 50 by $2 \mathrm{~mm}$ and $3-\mu \mathrm{m}$ particles (Phenomenex, Inc., Torrance, CA), maintained at $40^{\circ} \mathrm{C}$. S+ and $\mathrm{R}-$ carprofen was eluted at 4.4 and 4.9 min, respectively, whereas diclofenac was eluted at 4.5 min. Electrospray ionization (ESI) and full scan mass spectrometry was used for analyte detection. Carprofen was detected with negative ESI with MS3 fragmentation $(272 \rightarrow 228)$. Wideband activation in positive ESI mode was used to aid the loss of water from diclofenac during transition from the parent $(\mathrm{m} / \mathrm{z} 297)$ to the fragment ions. The sum of the intensities of ions at $\mathrm{m} / \mathrm{z}$ of 190, 226, and 228 were used for carprofen quantitation. The internal standard, diclofenac, was quantitated with the sum of the fragment ion intensities at $\mathrm{m} / \mathrm{z}$ of 215 , 250, and 252. Sequences consisting of plasma blanks, calibration spikes, and bovine plasma samples were batch processed with a processing method developed in the Xcalibur software (Thermo Scientific). The processing method automatically identified and integrated each peak in each sample and calculated the calibration curve based on a weighted $(1 / x)$ linear fit. Plasma concentrations of carprofen in unknown samples were calculated by the Xcalibur software based on the calibration curve. Results were then viewed in the Quan Browser portion of the Xcalibur software. Twelve calibration spikes were prepared in blank bovine plasma covering the concentration range of 5 to $20,000 \mathrm{ng} / \mathrm{mL}$. Calibration curves exhibited a correlation coefficient $\left(r^{2}\right)$ exceeding 0.996 across the entire concentration range. Quality control samples at 15, 150, and 1,500 $\mathrm{ng} / \mathrm{mL}$ were prepared in bulk and run with each set of samples/calibrators. The variance of the quality control samples was within 2 to $10 \%$ of the nominal value.

\section{Pharmacokinetic Analysis}

A noncompartmental pharmacokinetic analysis was performed using computer software. The following parameters were evaluated: area under the curve

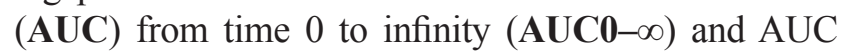
from time 0 to last collected sample (AUC0-96) using the linear trapezoidal rule as well as the percent of the AUC extrapolated to infinity. The extrapolated portion of the AUC was determined by multiplying the last measured plasma concentration by the elimination rate constant $(\boldsymbol{\lambda} \mathbf{z})$, the first-order terminal rate constant. The range of the $\lambda z$ was determined by visual inspection of the plasma profile and determined by linear regression of time and natural logarithm (ln) of the plasma concentration. The volume of distribution per bioavailability was determined by dividing the dose by $\lambda z \times A U C$. Plasma clearance per bioavailability was determined by dividing the dose by AUC. In addition, elimination half-life, maximum plasma concentration, and time to maximum plasma concentration were determined. The relative bioavailability (F) was estimated by dividing the oral (mean AUC/dose) by the subcutaneous (mean AUC/dose).

\section{Statistical Analysis}

Analyses were performed in SAS 9.3 (SAS Inst. Inc., Cary, NC) using a general linear mixed effects model with repeated measures using a heterogeneous compound symmetry covariance matrix. Data obtained from response variables including cortisol, SP, MNT, heart rate, and respiratory rate were natural logarithm transformed for normality. In addition, $\mathrm{PGE}_{2}$ percent inhibition was natural logarithm transformed for normality using the equation $\ln \left(\mathrm{PGE}_{2} \%\right.$ inhibition +101$)$ to transform the negative percent. Baseline values were used as covariates. The fixed effects were treatment (carprofen PO, carprofen SQ, PLCBO, and SHAM), time, and the interaction between treatment and time. The effect of sex was included for all statistical models. Phase was a random effect and calf was the subject of repeated measures. In order to test the significance of main effects and interactions, $F$-tests were used. If significant overall differences were identified among levels of a factor, pairwise comparisons were performed using Tukey's $t$ tests. Paired $t$ tests were performed to test the differences between LPSstimulated and unstimulated baseline ex vivo $\mathrm{PGE}_{2}$ concentrations. Planned contrasts were performed evaluating the responses of carprofen- (PO and SQ) versus PLCBO-treated calves following dehorning as well as the response following actual (PO, SQ, and PLCBO) or sham (SHAM) dehorning. These 3 contrasts are analyzed for the entire study along with at different time points $(4,8,12,24,48,72$, and $96 \mathrm{~h})$.

\section{RESULTS AND DISCUSSION}

The Animal Medicinal Drug Use Clarification Act (AMDUCA) permits the use of medicines to be used in an extra-label manner provided specific requirements are met (FDA, 1994). As no drugs are currently labeled in cattle for analgesia or those that are labeled as anti-inflammatory have unknown analgesic 
Table 2. Pharmacokinetic parameters following a noncompartmental analysis for carprofen (RS \pm ; Vedco, Inc., St. Joseph, MO) orally administered before cautery dehorning (mean dose, $1.4 \mathrm{mg} / \mathrm{kg}$; range, 1.13 to $1.63 \mathrm{mg} / \mathrm{kg}$ )

\begin{tabular}{|c|c|c|c|c|c|c|c|c|c|c|}
\hline \multirow[b]{2}{*}{ Parameter ${ }^{1}$} & \multicolumn{5}{|c|}{$\mathrm{R}(-)$} & \multicolumn{5}{|c|}{$\mathrm{S}(+)$} \\
\hline & Mean & SD & Minimum & Median & Maximum & Mean & SD & Minimum & Median & Maximum \\
\hline AUC extrapolated to $\infty, \%$ & 37.1 & 10.6 & 21.0 & 35.6 & 57.2 & 31.0 & 9.5 & 19.2 & 31.6 & 49.6 \\
\hline $\mathrm{AUC} 0 \rightarrow \infty, \mathrm{h} \times \mu \mathrm{g} / \mathrm{mL}$ & 518.2 & 143.4 & 321.1 & 519.5 & 786.8 & 394.5 & 114.6 & 239.8 & 371.0 & 565.5 \\
\hline $\mathrm{AUC} 0 \rightarrow 96 \mathrm{~h}, \mathrm{~h} \times \mu \mathrm{g} / \mathrm{mL}$ & 314.1 & 50.5 & 242.8 & 318.1 & 382.9 & 265.6 & 60.8 & 193.7 & 257.9 & 358.6 \\
\hline $\mathrm{Cl} / \mathrm{F}, \mathrm{mL} \cdot \mathrm{kg}^{-1} \cdot \mathrm{h}^{-1}$ & 1.45 & 0.41 & 0.89 & 1.36 & 2.18 & 1.92 & 0.57 & 1.24 & 1.89 & 2.92 \\
\hline $\mathrm{Cmax}, \mu \mathrm{g} / \mathrm{mL}$ & 4.41 & 0.63 & 3.53 & 4.58 & 5.16 & 3.94 & 0.84 & 2.82 & 3.70 & 5.14 \\
\hline $\mathrm{T} 1 / 2 \lambda z, \mathrm{~h}$ & 62.8 & 18.5 & 39.3 & 58.1 & 97.0 & 52.9 & 14.5 & 38.4 & 49.7 & 79.2 \\
\hline$\lambda z, 1 / \mathrm{h}$ & 0.012 & 0.0032 & 0.0071 & 0.012 & 0.018 & 0.014 & 0.0032 & 0.0088 & 0.014 & 0.018 \\
\hline Tmax, h & 26.4 & 12.4 & 12 & 24 & 48 & 22.8 & 14.4 & 12 & 18 & 48 \\
\hline $\mathrm{Vz} / \mathrm{F}, \mathrm{mL} / \mathrm{kg}$ & 124.0 & 23.7 & 93.2 & 117.7 & 161.2 & 140.8 & 36.5 & 90.3 & 138.1 & 210.1 \\
\hline
\end{tabular}

${ }^{1} \mathrm{AUC}=$ area under the curve; $\mathrm{AUC} 0 \rightarrow \infty=\mathrm{AUC}$ from time 0 to infinity; $\mathrm{AUC} 0 \rightarrow 96 \mathrm{~h}=\mathrm{AUC}$ from time 0 to last collected sample; $\mathrm{Cl} / \mathrm{F}=$ plasma clearance per bioavailability; $\mathrm{Cmax}=$ maximum plasma concentration; $\mathrm{T} 1 / 2 \lambda \mathrm{z}=$ elimination half-life; $\lambda \mathrm{z}=$ elimination rate constant; Tmax $=$ time to $\operatorname{maximum}$ plasma concentration; $\mathrm{Vz} / \mathrm{F}=$ volume of distribution per bioavailability.

properties following a single dose, the use of carprofen would constitute extra-label drug use permitted under AMDUCA. Following an intravenous (IV) or SQ dose of $1.4 \mathrm{mg} / \mathrm{kg}$, a 14-d slaughter withhold period is required in the European Union using the approved European formulation. Because there is a zero tolerance on the presence of violative residues under AMDUCA for extra-label drug use and carprofen demonstrates age-related pharmacokinetics, additional tissue residue studies are needed before recommendation of withholding times in young calves.

\section{Carprofen}

Carprofen was well absorbed following both subcutaneous and oral administration (Tables 2 and 3). Although carprofen is administered as a racemic mixture, the $\mathrm{S}(+)$ enantiomer has been reported to be primarily responsible for the observed PG inhibition (Brentnall et al., 2013). Using AUC0- $\infty$, the observed enantiomer ratio, R:S, was 57:43 for both oral and subcutaneous administration. This ratio is nearly identical to that previously reported following IV administration (Delatour et al., 1996). In the present study, both SQ and PO administration of carprofen demonstrated a small volume of distribution as well as a slow clearance, resulting in prolonged median half-lives, $\mathrm{S}(+)=52.8 \mathrm{~h}$ (range 38.3-180.7 h) and $S(+)=49.7 \mathrm{~h}$ (range 38.4-79.2 h), respectively. These values are longer than the previously published mean half-life of $43.4 \pm 2.3 \mathrm{~h}(\mathrm{RS} \pm$; $\mathrm{R}(-)$, $49.7 \pm 3.9 \mathrm{~h}$, and $\mathrm{S}(+), 37.4 \pm 2.4 \mathrm{~h})$ in 8 - to 10 -wk-old calves (Delatour et al., 1996). Carprofen-S(+) achieved a mean maximum concentrations of $5.3 \pm 0.9 \mu \mathrm{g} / \mathrm{mL}$ at $9 \mathrm{~h}$ following SQ administration and $3.9 \pm 0.8 \mu \mathrm{g} / \mathrm{mL}$ at $18 \mathrm{~h}$ following PO dosing. The relative bioavailability of PO carprofen in comparison with SQ calculated using mean AUC0-96 was approximately $70 \%$.

The pharmacokinetics in the present study indicated a longer mean half-life than previously reported in animals of similar age (Delatour et al., 1996). This may

Table 3. Pharmacokinetic parameters following a noncompartmental analysis for carprofen (RS \pm ; Pfizer Inc., New York, NY) subcutaneously administered before cautery dehorning $(1.4 \mathrm{mg} / \mathrm{kg})$

\begin{tabular}{|c|c|c|c|c|c|c|c|c|c|c|}
\hline \multirow[b]{2}{*}{ Parameter ${ }^{1}$} & \multicolumn{5}{|c|}{$\mathrm{R}(-)$} & \multicolumn{5}{|c|}{$\mathrm{S}(+)$} \\
\hline & Mean & SD & Minimum & Median & Maximum & Mean & SD & Minimum & Median & Maximum \\
\hline AUC extrapolated to $\infty, \%$ & 43.1 & 16.1 & 26.5 & 42.1 & 77.2 & 33.9 & 15.5 & 19.3 & 29.7 & 70.3 \\
\hline $\mathrm{AUC} 0 \rightarrow \infty, \mathrm{h} \times \mu \mathrm{g} / \mathrm{mL}$ & 753.6 & 458.5 & 383.5 & 656.3 & $1,969.6$ & 557.7 & 368.6 & 266.2 & 433.1 & $1,526.5$ \\
\hline $\mathrm{AUC} 0 \rightarrow 96 \mathrm{~h}, \mathrm{~h} \times \mu \mathrm{g} / \mathrm{mL}$ & 369.6 & 59.6 & 284.1 & 369.4 & 463.2 & 319.6 & 77.7 & 214.9 & 307.0 & 452.7 \\
\hline $\mathrm{Cl} / \mathrm{F}, \mathrm{mL} \cdot \mathrm{kg}^{-1} \cdot \mathrm{h}^{-1}$ & 1.14 & 0.45 & 0.34 & 1.06 & 1.80 & 1.58 & 0.63 & 0.46 & 1.62 & 2.63 \\
\hline $\mathrm{Cmax}, \mu \mathrm{g} / \mathrm{mL}$ & 5.74 & 0.57 & 4.76 & 5.66 & 6.74 & 5.27 & 0.85 & 4.24 & 5.10 & 6.61 \\
\hline $\mathrm{T} 1 / 2 \lambda \mathrm{z}, \mathrm{h}$ & 89.3 & 58.6 & 47.9 & 75.7 & 242.7 & 66.7 & 42.6 & 38.3 & 52.8 & 180.7 \\
\hline$\lambda z, 1 / h$ & 0.0098 & 0.0040 & 0.0029 & 0.0092 & 0.014 & 0.013 & 0.0043 & 0.0038 & 0.013 & 0.018 \\
\hline Tmax, h & & & 6 & 6 & 12 & & & 6 & 9 & 12 \\
\hline $\mathrm{Vz} / \mathrm{F}, \mathrm{mL} / \mathrm{kg}$ & 118.3 & 16.1 & 79.3 & 122.2 & 138.3 & 124.5 & 20.6 & 90.9 & 130.5 & 147.3 \\
\hline
\end{tabular}

${ }^{1} \mathrm{AUC}=$ area under the curve; $\mathrm{AUC} 0 \rightarrow \infty=\mathrm{AUC}$ from time 0 to infinity; $\mathrm{AUC} 0 \rightarrow 96 \mathrm{~h}=\mathrm{AUC}$ from time 0 to last collected sample; $; \mathrm{Cl} / \mathrm{F}=\mathrm{plasma}$ clearance per bioavailability; $\mathrm{Cmax}=$ maximum plasma concentration; $\mathrm{T} 1 / 2 \lambda \mathrm{z}=$ elimination half-life; $\lambda \mathrm{z}=$ elimination rate constant; Tmax $=$ time to maximum plasma concentration; $\mathrm{Vz} / \mathrm{F}=$ volume of distribution per bioavailability. 
be a result of using a younger population of animals in the present study. Age-dependent pharmacokinetics of carprofen has been reported in calves, with concentrations persisting longer in younger animals (Delatour et al., 1996; Brentnall et al., 2013). Longer half-lives in younger calves are suggested to be a result of a reduction in clearance, which is consistent with our findings (Lees et al., 1996, Delatour et al., 1996). It should be

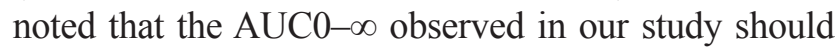
be interpreted with caution due to the large percent of the AUC extrapolated to infinity.

Analgesic concentrations of NSAID have been previously estimated using a calculated $80 \%$ inhibitory concentration $\left(\mathbf{I C}_{\mathbf{8 0}}\right)$ concentration of COX-2 inhibition (Lees et al., 2004; Huntjens et al., 2005). A recent study evaluating in vitro COX-2 inhibition using a bovine whole blood assay indicted an $\mathrm{IC}_{80}$ equal to a mean total carprofen ( $\mathrm{RS} \pm$ ) concentration of 8.9 $\mu \mathrm{g} / \mathrm{mL}$ (range 1.9-42.9 $\mu \mathrm{g} / \mathrm{mL}$; Miciletta et al., 2014). Interestingly, it was reported that the $\mathrm{R}(-)$ enantiomer may attenuate COX inhibitory activity of the $\mathrm{S}(+)$ enantiomer (Miciletta et al., 2013). Assuming these concentrations provide pain relief, using total carprofen concentrations with a similar enantiomer ratio as derived in our study, SQ administration would provide analgesia from approximately 4 to $24 \mathrm{~h}$ of time; however, a direct comparison between studies should be interpreted with caution given differences in study design. Oral administration did not achieve this target mean concentration throughout the course of the study. These data would potentially support the current daily regimen of SQ administration to achieve the previously reported $\mathrm{IC}_{80}$; however, the duration above the $\mathrm{IC}_{80}$ observed in this study is shorter than that previously reported using the $\mathrm{S}(+)$ enantiomer alone (Brentnall et al., 2013). This may due to the interaction of the $\mathrm{R}(-)$ enantiomer given the enantioselectivity observed following administration of the racemic mixture in calves as reported by Miciletta et al. (2014).

\section{Prostaglandin $E_{2}$}

An effect of treatment $(P<0.0001)$ and time $(P$ $<0.0001)$ was observed on $\mathrm{PGE}_{2}$ percent inhibition (Table 4). Moreover, there was an interaction of time and treatment $(P<0.0001)$. Percent inhibition was increased for calves subcutaneously administered carprofen compared with placebo-treated controls from the initial collection time point of $2 \mathrm{~h}$ through $72 \mathrm{~h}(P<0.05$; Fig. 2). In addition, the percent inhibition was increased in calves orally treated with carprofen from 6 through 96 h compared with placebo-treated controls $(P<0.05$; Fig. 2). Prostaglandin percent inhibition was significantly decreased in sham-dehorned calves compared with calves treated with carprofen for all time points $(P<$ $0.05)$. No difference was observed in PG inhibition between placebo-treated dehorned calves compared with those sham dehorned $(P>0.1)$. Baseline PGE concentrations of LPS-stimulated blood was greater than unstimulated blood $(P<0.0001)$.

Nonsteroidal anti-inflammatory drugs inhibit COX isoenzymes responsible for producing $\mathrm{PG}$, which increase nociception, thereby increasing the sensitivity for nerve transmission at the site of injury (Basbaum et al., 2009). Carprofen is known to be a weak inhibitor of cyclcoxygenase (Delatour et al., 1996; Lees et al., 1996). As such, the mechanism of action of this NSAID is thought to be both COX dependent and COX independent. In addition to inhibition of PG (Brentnall et al., 2013; Miciletta et al., 2013, 2014), the effect of carprofen may be mediated through reductions in proinflammatory IL-6, observed in an equine in vitro study (Armstrong and Lees, 2002). In our study, ex vivo PGE concentrations were persistently decreased for the duration of the study in carprofen-treated calves compared with placebo-treated controls; however, only a moderate overall reduction was observed in comparison with other NSAID demonstrating up to $100 \%$ PG inhibition using tissue cage models evaluating $\mathrm{PGE}_{2}$ inhibition in exudate (Lees et al., 2004).

Multiple studies have used in vitro assays to measure the effect and potency of carprofen on PGE inhibition (Brentnall et al., 2013; Miciletta et al., 2014). However, in our study, ex vivo PGE inhibition was used to determine the duration of effect following a single dose. Determination of ex vivo PGE concentrations in-

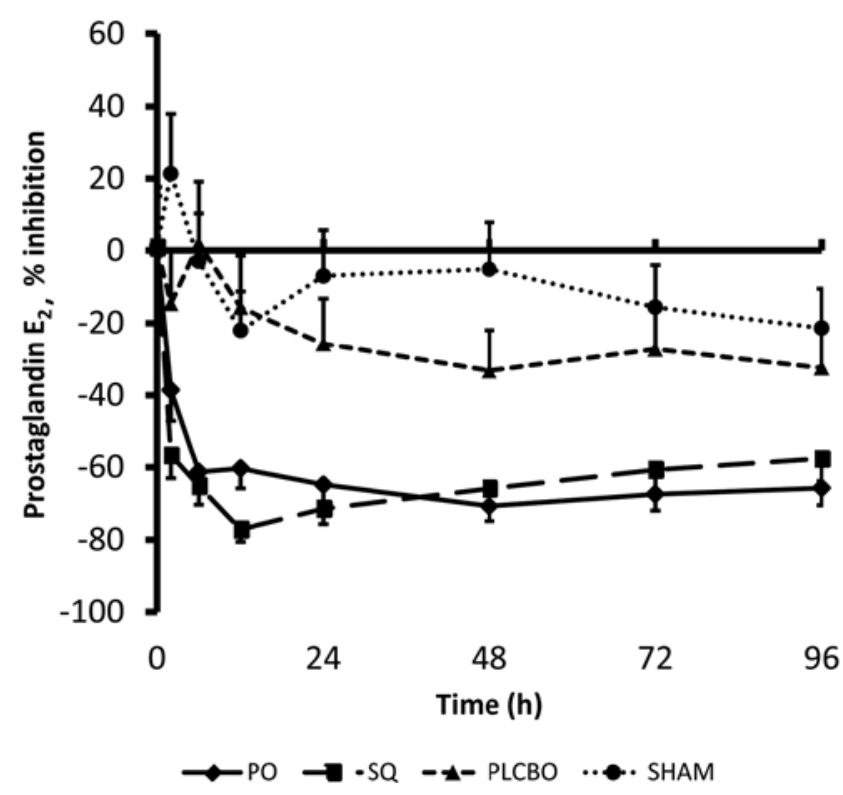

Figure 2. Back transformed mean $( \pm \mathrm{SE})$ ex vivo $\mathrm{PGE}_{2}$ percent inhibition over $96 \mathrm{~h}$ in carprofen- and placebo-treated calves after dehorning. $\mathrm{PO}=$ oral carprofen, dehorned group; $\mathrm{SQ}=$ subcutaneous carprofen, $\mathrm{de}-$ horned group; PLCBO = placebo-treated dehorned group; SHAM = nondehorned, placebo treated group. 

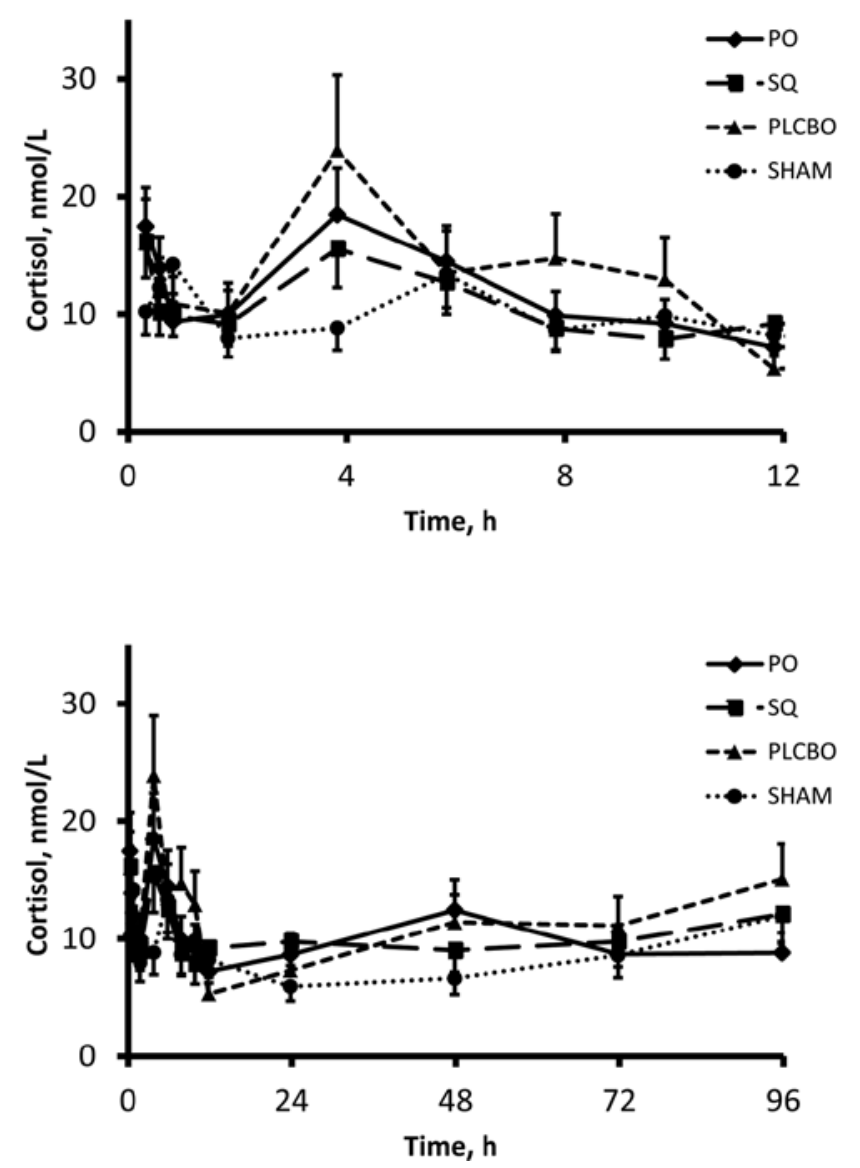

Figure 3. Back transformed geometric mean $( \pm \mathrm{SE})$ cortisol concentrations over 12 (a) and $96 \mathrm{~h}$ (b) for carprofen- and placebo-treated calves after cautery dehorning. Time 0 signifies the time of dehorning. $\mathrm{PO}=$ oral carprofen, dehorned group; $\mathrm{SQ}$ = subcutaneous carprofen, dehorned group; PLCBO = placebo-treated dehorned group; SHAM = non-dehorned, placebo treated group.

cludes the effect of the parent compound in in vivo enantiomer ratios as well as any contribution from circulating metabolites. It is unknown if carprofen metabolites are responsible for inhibition of PG. Glucuronide and CoA thioester metabolites of ketoprofen, an NSAID of the same 2-arylpropionic acid class as carprofen, demonstrate potent PG inhibition in vitro (Levoin et al., 2004). Although not measured in this study, active metabolites may explain the observed difference in inhibition of PGE between carprofen- and placebo-treated calves that persisted longer than $48 \mathrm{~h}$ with decreasing parent drug concentrations.

\section{Cortisol}

There was no effect of treatment on cortisol concentrations $(P=0.48)$. Cortisol concentrations were affected over time $(P<0.0001$; Fig. 3$)$; however, there was no interaction of time and treatment $(P=0.22$; Table 4). No treatment differences were observed in evaluating the overall cortisol (AUEC from time 0 to last collected sample; $P=0.51$ ). Furthermore, no treat- ment differences were observed when the AUEC was divided as follows: 0 to $2(P=0.64), 2$ to $8(P=0.34)$, and 8 to $96 \mathrm{~h}(P=0.55$; Table 5$)$.

Cortisol concentrations have been previously described to increase in calves dehorned compared with those sham dehorned (Stafford and Mellor, 2005). Although changes in cortisol concentrations were observed over time in this study, no overall treatment differences among the groups were observed. This differs from a previous study that reported decreased cortisol concentrations at $1 \mathrm{~h}$ after cautery disbudding compared with placebo-treated controls (Stilwell et al., 2012). These differences may be due to the route of administration, as carprofen was intravenously administered in the previous study, potentially rapidly achieving greater concentrations.

Evaluating the effect of carprofen on the stress response in nonsurgical castration has yielded equivocal results in older, 6-mo-old calves. A nonsignificant reduction in cortisol was observed in 1 study after IV carprofen $(1.4 \mathrm{mg} / \mathrm{kg})$ was given $20 \mathrm{~min}$ before band castration (Pang et al., 2006), whereas another study reported a significant decrease of cortisol 6 and $48 \mathrm{~h}$ after burdizzo clamp castration in calves subcutaneously treated with carprofen $(1.4 \mathrm{mg} / \mathrm{kg}$; Stilwell et al., 2008 b). Additional study is needed to determine the effect of carprofen on the stress response following noxious stimuli.

\section{Substance P}

There was no effect of treatment $(P=0.77)$, time $(P$ $=0.23)$, or interaction of time and treatment $(P=0.53)$ on SP concentrations (Table 4). Area under the effect curve and maximum SP concentrations were not different among treatment groups (Table 5). In response to cautery dehorning, meloxicam (Allen et al., 2013) administration decreased SP concentrations where as firocoxib (Stock et al., 2015) did not result in a difference compared with placebo-treated controls. Taken together with the lack of cortisol treatment differences, carprofen administered at the study dose and routes given may not provide adequate analgesia following cautery dehorning.

Interestingly, an effect of gender was observed $(P=0.005)$. with SP concentrations greater $(0.11 \pm$ $0.039 \mathrm{pg} / \mathrm{mL}$ ) in female calves compared with male calves. Differences in pain responses between sexes have been previously well documented (Fillingim et al., 2009). More recently, SP differences between sexes were reported in a rat model using a formalinevoked pain model resulting in SP release (Nazarian et al., 2014). Consistent with our study, female rats had an increase in SP release, which was determined to 
Table 4. Summary table of backtransformed response variables (geometric means [ $95 \%$ confidence interval]) of carprofen- and placebo-treated calves after dehorning. $n=10$ unless otherwise noted

\begin{tabular}{|c|c|c|c|c|c|c|c|}
\hline \multirow[b]{3}{*}{ Response } & \multicolumn{2}{|c|}{ Carprofen $^{1}$} & \multicolumn{2}{|c|}{ Control $^{2}$} & \multirow{3}{*}{$\begin{array}{c}\text { Treatment, } \\
P \text {-value }\end{array}$} & \multirow{3}{*}{$\begin{array}{l}\text { Time, } \\
P \text {-value }\end{array}$} & \multirow{3}{*}{$\begin{array}{c}\text { Time } \times \\
\text { treatment, } \\
P \text {-value }\end{array}$} \\
\hline & SQ & $\mathrm{PO}$ & PLCBO & SHAM & & & \\
\hline & \multicolumn{4}{|c|}{ Mean ( $95 \%$ confidence interval) } & & & \\
\hline $\mathrm{MNT},{ }^{3} \mathrm{kgf}$ & $\begin{array}{c}0.71^{\mathrm{a}} \\
(0.56 \text { to } 0.88)\end{array}$ & $\begin{array}{c}0.72^{\mathrm{a}} \\
(0.57 \text { to } 0.90)\end{array}$ & $\begin{array}{c}0.58^{\mathrm{a}} \\
(0.46 \text { to } 0.73)\end{array}$ & $\begin{array}{c}1.84^{\mathrm{b}} \\
(1.47 \text { to } 2.32)\end{array}$ & $<0.0001$ & $<0.0001$ & 0.99 \\
\hline $\begin{array}{l}\text { Ocular } \\
\text { temperature, }{ }^{\circ} \mathrm{C}\end{array}$ & $\begin{array}{c}38.4^{\mathrm{a}} \\
(37.7 \text { to } 39.0)\end{array}$ & $\begin{array}{c}38.5^{\mathrm{a}} \\
\text { (37.9 to } 39.2)\end{array}$ & $\begin{array}{c}38.1^{\mathrm{a}} \\
(37.5 \text { to } 38.8)\end{array}$ & $\begin{array}{c}38.2^{\mathrm{a}} \\
(37.6 \text { to } 38.9)\end{array}$ & 0.65 & $<0.0001$ & 0.26 \\
\hline $\begin{array}{l}\text { Heart rate, } \\
\text { beats } / \mathrm{min}\end{array}$ & $\begin{array}{c}94.3^{\mathrm{a}} \\
(87.3 \text { to } 101.9)\end{array}$ & $\begin{array}{c}98.5^{\mathrm{a}} \\
\text { (91.3 to } 106.2)\end{array}$ & $\begin{array}{c}97.0^{\mathrm{a}} \\
\text { (89.9 to } 104.6)\end{array}$ & $\begin{array}{c}90.4^{\mathrm{a}} \\
\text { (83.7 to } 97.8)\end{array}$ & 0.43 & 0.0092 & 0.96 \\
\hline $\begin{array}{l}\text { Respiratory rate, } \\
\text { breaths/min }\end{array}$ & $\begin{array}{c}40.5^{\mathrm{a}} \\
\text { (37.1 to } 44.1)\end{array}$ & $\begin{array}{c}38.4^{\mathrm{a}} \\
\text { (35.2 to } 41.8)\end{array}$ & $\begin{array}{c}36.1^{\mathrm{a}} \\
\text { (33.1 to } 39.3)\end{array}$ & $\begin{array}{c}38.4^{\mathrm{a}} \\
(35.2 \text { to } 41.8)\end{array}$ & 0.20 & 0.086 & 0.25 \\
\hline $\mathrm{ADG}, \mathrm{kg} / \mathrm{d}$ & $\begin{array}{c}0.48^{\mathrm{a}} \\
(0.27 \text { to } 0.68)\end{array}$ & $\begin{array}{c}0.92^{\mathrm{b}} \\
(0.71 \text { to } 1.12)\end{array}$ & $\begin{array}{c}0.69^{\mathrm{ab}} \\
(0.48 \text { to } 0.90)\end{array}$ & $\begin{array}{c}0.68^{\mathrm{ab}} \\
(0.47 \text { to } 0.88)\end{array}$ & 0.0081 & & \\
\hline Cortisol, $\mathrm{nmol} / \mathrm{L}$ & $\begin{array}{c}10.5^{\mathrm{a}} \\
\text { (8.4 to } 13.2)\end{array}$ & $\begin{array}{c}11.0^{\mathrm{a}} \\
\text { (8.7 to } 13.8)\end{array}$ & $\begin{array}{c}11.9^{\mathrm{a}} \\
(9.5 \text { to } 15.0)\end{array}$ & $\begin{array}{c}9.4^{\mathrm{a}} \\
\text { (7.5 to } 11.9)\end{array}$ & 0.48 & $<0.0001$ & 0.22 \\
\hline $\begin{array}{l}\text { Substance } \mathrm{P} \\
\mathrm{pg} / \mathrm{mL}\end{array}$ & $\begin{array}{c}16.3^{\mathrm{a}} \\
(14.2 \text { to } 18.7)\end{array}$ & $\begin{array}{c}17.0^{\mathrm{a}} \\
(14.8 \text { to } 19.5)\end{array}$ & $\begin{array}{c}17.0^{\mathrm{a}} \\
(14.8 \text { to } 19.5)\end{array}$ & $\begin{array}{c}16.4^{\mathrm{a}} \\
(14.3 \text { to } 18.9)\end{array}$ & 0.77 & 0.23 & 0.53 \\
\hline $\mathrm{PGE}_{2}, \%$ & $\begin{array}{c}-65.6^{4 a} \\
(-73.7 \text { to }-55.2)\end{array}$ & $\begin{array}{c}-62.2^{\mathrm{a}} \\
(-70.7 \text { to }-51.5)\end{array}$ & $\begin{array}{c}-21.7^{4 b} \\
(-39.8 \text { to } 1.6)\end{array}$ & $\begin{array}{c}-8.3^{\mathrm{b}} \\
(-28.5 \text { to } 17.5)\end{array}$ & $<0.0001$ & $<0.0001$ & $<0.0001$ \\
\hline
\end{tabular}

a,b Within a row, means without a common superscript differ $(P<0.05)$.

${ }^{1} \mathrm{SQ}=$ subcutaneous carprofen, dehorned group; $\mathrm{PO}=$ oral carprofen, dehorned group.

${ }^{2} \mathrm{PLCBO}=$ placebo-treated dehorned group; SHAM = non-dehorned, placebo treated group.

${ }^{3} \mathrm{MNT}=$ mechanical nociception threshold.

${ }^{4} n=9$.

Table 5. Area under the effect curve and maximum cortisol and substance P concentration (geometric means [95\% confidence intervals]) of carprofen- and placebo-treated calves after dehorning. $n=10$ for all response variables evaluated

\begin{tabular}{|c|c|c|c|c|c|}
\hline \multirow[b]{3}{*}{ Response $^{1}$} & \multicolumn{2}{|c|}{ Carprofen $^{2}$} & \multicolumn{2}{|c|}{ Control $^{3}$} & \multirow[b]{3}{*}{$P$-valuc } \\
\hline & SQ & $\mathrm{PO}$ & PLCBO & SHAM & \\
\hline & \multicolumn{4}{|c|}{ Mean ( $95 \%$ confidence interval) } & \\
\hline \multicolumn{6}{|c|}{ Cortisol, $\mathrm{nmol} \times \mathrm{h} / \mathrm{L}$} \\
\hline AUEC $_{0-96}$ & $\begin{array}{c}1,087.9^{\mathrm{a}} \\
(814.1 \text { to } 1,453.7)\end{array}$ & $\begin{array}{c}1,145.8^{\mathrm{a}} \\
\text { (850.9 to } 1,542.9)\end{array}$ & $\begin{array}{c}1,201.8^{\mathrm{a}} \\
(896.1 \text { to } 1,612.0)\end{array}$ & $\begin{array}{c}898.4^{\mathrm{a}} \\
\text { (669.6 to } 1,205.3)\end{array}$ & 0.51 \\
\hline $\mathrm{AUEC}_{0-2}$ & $\begin{array}{c}16.3^{\mathrm{a}} \\
(12.1 \text { to } 21.8)\end{array}$ & $\begin{array}{c}17.5^{\mathrm{a}} \\
(13.0 \text { to } 23.7)\end{array}$ & $\begin{array}{c}20.0^{\mathrm{a}} \\
(14.8 \text { to } 26.9)\end{array}$ & $\begin{array}{c}19.5^{\mathrm{a}} \\
(14.5 \text { to } 26.3)\end{array}$ & 0.64 \\
\hline $\mathrm{AUEC}_{2-8}$ & $\begin{array}{c}80.1^{\mathrm{a}} \\
(55.7 \text { to } 115.2)\end{array}$ & $\begin{array}{c}94.0^{\mathrm{a}} \\
(64.8 \text { to } 136.5)\end{array}$ & $\begin{array}{c}108.4^{\mathrm{a}} \\
(75.1 \text { to } 156.6)\end{array}$ & $\begin{array}{c}69.6^{\mathrm{a}} \\
\text { (48.2 to } 100.6)\end{array}$ & 0.34 \\
\hline $\mathrm{AUEC}_{8-96}$ & $\begin{array}{c}978.7^{\mathrm{a}} \\
\text { (715.4 to } 1,338.9)\end{array}$ & $\begin{array}{c}1,022.1^{\mathrm{a}} \\
(740.9 \text { to } 1,409.9)\end{array}$ & $\begin{array}{c}1,058.1^{\mathrm{a}} \\
(770.3 \text { to } 1,453.2)\end{array}$ & $\begin{array}{c}789.6^{\mathrm{a}} \\
\text { (574.6 to } 1,084.9 \text { ) }\end{array}$ & 0.55 \\
\hline $\mathrm{Cmax}, \mathrm{nmol} / \mathrm{L}$ & $\begin{array}{c}30.5^{\mathrm{a}} \\
\text { (24.3 to } 38.4)\end{array}$ & $\begin{array}{c}29.4^{\mathrm{a}} \\
(23.3 \text { to } 37.2)\end{array}$ & $\begin{array}{c}35.7^{\mathrm{a}} \\
(28.3 \text { to } 45.0)\end{array}$ & $\begin{array}{c}28.1^{\mathrm{a}} \\
(22.3 \text { to } 35.4)\end{array}$ & 0.41 \\
\hline \multicolumn{6}{|c|}{ Substance $\mathrm{P}, \mathrm{pg} \times \mathrm{h} / \mathrm{mL}$} \\
\hline $\mathrm{AUEC}_{0-96}$ & $\begin{array}{c}1,599.3^{\mathrm{a}} \\
(1,342.8 \text { to } 1,904.7)\end{array}$ & $\begin{array}{c}1,625.5^{\mathrm{a}} \\
(1,364.9 \text { to } 1,936.2)\end{array}$ & $\begin{array}{c}1,622.0^{\mathrm{a}} \\
(1,361.6 \text { to } 1,932.4)\end{array}$ & $\begin{array}{c}1,586.5^{\mathrm{a}} \\
(1,332.0 \text { to } 1,889.9)\end{array}$ & 0.96 \\
\hline $\mathrm{AUEC}_{0-8}$ & $\begin{array}{c}124.6^{\mathrm{a}} \\
(107.4 \text { to } 144.5)\end{array}$ & $\begin{array}{c}129.7^{\mathrm{a}} \\
(111.8 \text { to } 150.5)\end{array}$ & $\begin{array}{c}134.8^{\mathrm{a}} \\
\text { (116.1 to } 156.4)\end{array}$ & $\begin{array}{c}131.0^{\mathrm{a}} \\
(112.9 \text { to } 152.0)\end{array}$ & 0.70 \\
\hline $\mathrm{AUEC}_{8-96}$ & $\begin{array}{c}1,473.9^{\mathrm{a}} \\
(1,232.4 \text { to } 1,762.9)\end{array}$ & $\begin{array}{c}1,494.4^{\mathrm{a}} \\
(1,249.5 \text { to } 1,787.5)\end{array}$ & $\begin{array}{c}1,486.7^{\mathrm{a}} \\
(1,242.6 \text { to } 1,778.5)\end{array}$ & $\begin{array}{c}1,454.5^{\mathrm{a}} \\
(1,215.9 \text { to } 1,739.9)\end{array}$ & 0.96 \\
\hline Cmax, pg/mL & $\begin{array}{c}23.1^{\mathrm{a}} \\
\text { (18.9 to } 28.2)\end{array}$ & $\begin{array}{c}23.1^{\mathrm{a}} \\
\text { (18.9 to } 28.3)\end{array}$ & $\begin{array}{c}23.6^{\mathrm{a}} \\
\text { (19.3 to } 28.8)\end{array}$ & $\begin{array}{c}22.9^{\mathrm{a}} \\
\text { (18.7 to } 27.9)\end{array}$ & 0.98 \\
\hline
\end{tabular}

${ }^{a}$ Within a row, means without a common superscript differ $(P<0.05)$.

${ }^{1} \mathrm{AUEC}_{0-96}=$ area under the effect curve from time 0 to last collected sample; $\mathrm{AUEC}_{0-2}=$ area under the effect curve from time 0 to $2 \mathrm{~h} ; \mathrm{AUEC}_{2-8}=$ area under the effect curve from time 2 to $8 \mathrm{~h} ; \mathrm{AUEC}_{8-96}=$ area under the effect curve from time 8 to last collected sample; $\mathrm{AUEC}_{0-8}=$ area under the effect curve from time 0 to $8 \mathrm{~h} ; \mathrm{AUEC}_{8-96}=$ area under the effect curve from time 8 to last collected sample; $\mathrm{Cmax}=$ maximum plasma concentration.

${ }^{2} \mathrm{SQ}=$ subcutaneous carprofen, dehorned group; $\mathrm{PO}=$ oral carprofen, dehorned group.

${ }^{3} \mathrm{PLCBO}=$ placebo-treated dehorned group; SHAM = non-dehorned, placebo treated group. 


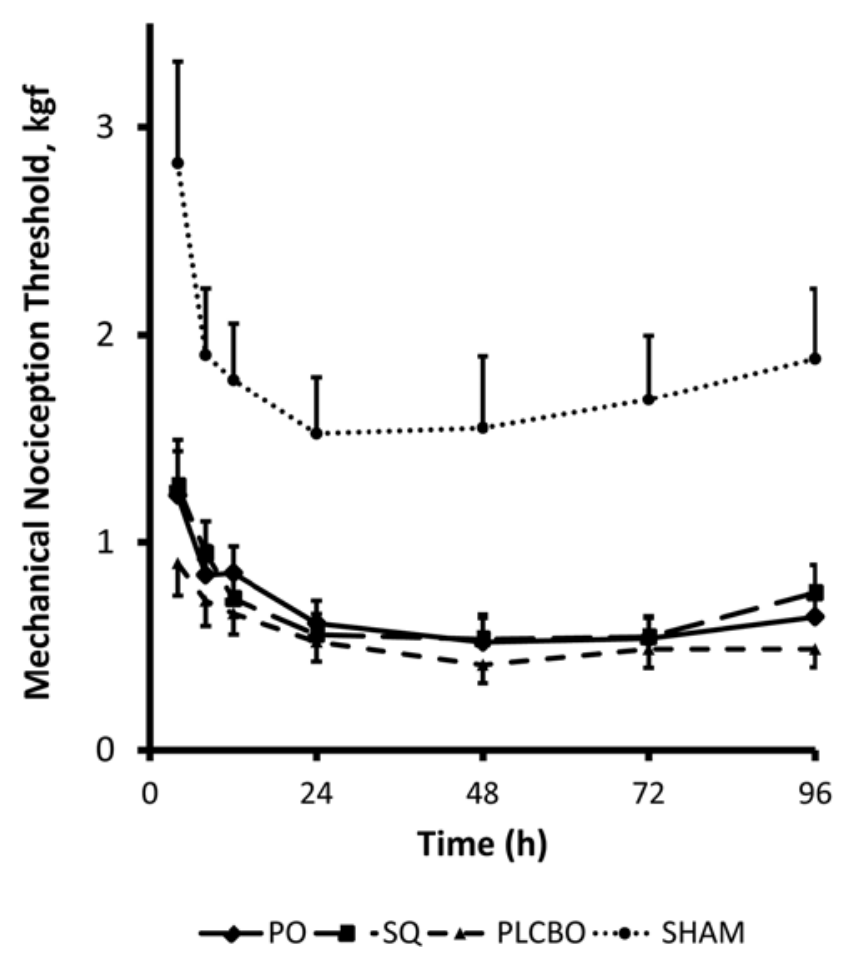

Figure 4. Backtransformed geometric mean $( \pm \mathrm{SE})$ mechanical nociception threshold (MNT) as measured through pressure algometry over $96 \mathrm{~h}$ for carprofen- and placebo-treated calves. Time 0 signifies the time of dehorning. Pressure tolerance did not return to baseline values by the conclusion of MNT measurement for animals dehorned. Sham dehorned animals were significantly different at all time points after dehorning $(P<$ $0.0001) . P O=$ oral carprofen, dehorned group; $\mathrm{SQ}=$ subcutaneous carprofen, dehorned group; PLCBO = placebo-treated dehorned group; SHAM = non-dehorned, placebo treated group.

be mediated by estradiol concentrations. In our study, although a difference was noted, the effect size was small. Additionally, previous castration in males may confound the observed results in this study. Additional studies are needed to further clarify the role of sexual dimorphism in SP release in cattle.

\section{Mechanical Nociception Threshold}

An effect of treatment was observed $(P<0.0001)$ on the mean MNT. Furthermore, there was an effect of time $(P<0.0001)$ but there was no interaction between treatment and time $(P=0.99$; Table 4$)$. Sham-dehorned calves had an increased MNT at all collection time points $(P<0.001$; Table 4; Fig. 4). No overall treatment differences were observed among individual treatment groups of dehorned calves; however, the overall mean MNT tended to be greater in carprofen-treated calves compared with those administered a placebo $(P=0.097)$.

Previous studies have evaluated MNT differences following actual or sham dehorning of calves (Heinrich et al., 2010; Tapper et al., 2011; Allen et al., 2013, Glynn et al., 2013). In these previous studies, calves were initially sham dehorned before actual dehorning to determine baseline MNT information. In this study, in addition to determining baseline MNT values, shamdehorned calves were included throughout the data collection period to help control for the effects of the study on the pressure algometry response. Due to the MNT differences observed between sham and actual dehorned calves throughout the study period, MNT appears to be a reliable measure of increased pain sensitivity associated with cautery dehorning. Although MNT did not return to baseline values following the duration of the study ( $4 \mathrm{~d}$ ) for dehorned calves, partial thickness epidermal burns have been noted to induce mechanical hyperalgesia for up to $4 \mathrm{wk}$ in rat thermal injury models (Summer et al., 2007).

Mechanical nociception threshold has been useful in detecting nociception differences in dehorned calves treated with an analgesic. Heinrich et al. (2010) demonstrated decreased sensitivity as determined by increased MNT following the use of intramuscular meloxicam. Moreover, Tapper et al. (2011) reported an increased MNT in calves administered local anesthesia using ethanol for at least $3 \mathrm{~d}$ after dehorning compared with calves administered lidocaine. Although carprofen administration tended to increase MNT throughout the study period, further investigation is warranted to determine the improved sensitivity associated with carprofen administration.

\section{Ocular Temperature}

There was no effect of treatment on ocular temperature $(P=0.65)$. An effect of time was observed ( $P$ $<0.0001)$; however, there was no interaction of time and treatment $(P=0.26$; Table 4$)$. Statistical analysis of the average ocular temperature yielded results similar to the presented minimum recorded maximum ocular temperature. Previous studies have indicated an equivocal response of ocular temperature following dehorning. Stewart et al. (2009) reported a decreased ocular temperature associated with the loss of local anesthesia following dehorning. Moreover, administration of meloxicam attenuated the decreased ocular temperature observed in placebo-treated calves after dehorning (Stewart et al., 2009); however, other investigations have not observed this same response (Glynn et al., 2013; Allen et al., 2013; Stock et al., 2015). Differences in handling, study animals, and data collection technique may account for the different results among studies. The similar ocular temperature profiles throughout the study of sham and actual dehorned calves might further support this statement. 


\section{Heart Rate}

There was no effect of treatment on heart rate $(P$ $=0.43)$. An effect of time was observed $(P=0.0092)$; however, there was no interaction between treatment and time $(P=0.96$; Table 4$)$. Heart rate has been previously used to evaluate changes in the autonomic nervous system following noxious events in cattle (Stewart et al., 2009; Heinrich et al., 2010; Coetzee et al., 2012). Increased heart rate variability has been reported in castrated or dehorned cattle as a result of an imbalance in the autonomic nervous system (Stewart et al., 2009; Stewart et al., 2008). Although previous reports have indicated a significant reduction in heart rate in calves administered meloxicam before dehorning, this effect was not observed in our study (Heinrich et al., 2010; Coetzee et al., 2012). Differences in analgesic potential between NSAID and method of data collection may be reasons for the reported differences. In previous investigations, heart rates were collected using an electrical heart rate monitor (Coetzee et al., 2012) or obtained following blood collection (Heinrich et al., 2009), which differs from our study. It is noteworthy that no differences were observed between calves actually or sham dehorned, potentially indicating the influence of the repeated handling for data collection.

\section{Respiratory Rate}

Statistical analysis was performed with and without calves treated for respiratory disease. Using data from all calves, respiratory rate was not affected by treatment $(P=0.20)$ or time $(P=0.086$; Table 4$)$. Moreover, treatment groups did not differ in response over time $(P=0.25)$. Although carprofen-treated calves tended to have an increased respiratory rate in comparison with placebo-treated calves $(P=0.094)$, this effect was not observed if calves treated for respiratory disease were removed from the statistical analysis $(P=0.38)$. These results differ from a previous report of increasing respiratory rates in placebo-treated calves compared with calves treated with meloxicam (Heinrich et al., 2009). The lack of agreement between studies may be due to differences in analgesic potential between NSAID, study design including housing differences, and the technique used to collect the data (Heinrich et al., 2009).

\section{Average Daily Gain}

Calves treated with oral carprofen had an increased ADG compared with those treated with subcutaneous carprofen $(0.92 \pm 0.10$ vs. $0.48 \pm 0.10 \mathrm{~kg} / \mathrm{d} ; P=0.0039)$. No other differences were observed between treatment groups $(P>0.1)$. Changes in ADG are equivocal, with previous studies reporting no changes or increases compared with placebo-treated controls (Baldridge et al., 2011; Glynn et al., 2013; Coetzee et al., 2012 ; Stock et al., 2015). Greater increases were observed in older study populations undergoing amputation dehorning, suggesting the potential that dehorning has a larger impact on weight gain in older calves after an invasive procedure (Baldridge et al., 2011; Glynn et al., 2013; Coetzee et al., 2012 ). We do not completely understand the exact mechanism of the difference in ADG observed between carprofen treatments in our study and these differences may be a result of the small number of animals enrolled in each treatment group. Parameters that contribute to changes in ADG such as grain consumption were not measured in our study. Given the sample size used in this study, further investigations into changes in ADG following carprofen administration are warranted.

\section{Conclusion}

Cautery dehorning in dairy calves resulted in increased nociception throughout the 96-h study period. Carprofen administration reached concentrations that moderately inhibited ex vivo PG and were decreased for 72 (SQ) and $96 \mathrm{~h}$ (PO) after administration compared with placebo-treated controls; however, analgesic responses between treatment groups subsequent to dehorning were minimal using a dose of $1.4 \mathrm{mg} / \mathrm{kg}$ administered orally or subcutaneously. Consideration of route of administration and dose determination studies are recommended.

\section{LITERATURE CITED}

Allen, K. A., J. F. Coetzee, L. N. Edwards-Callaway, H. Glynn, J. Dockweiler, B. KuKanich, H. Lin, C. Wang, E. Fraccaro, M. Jones, and L. Bergamasco. 2013. The effect of timing of oral meloxicam administration on physiological responses in calves after cautery dehorning with local anesthesia. J. Dairy Sci. 96:5194-5205. doi:10.3168/jds.2012-6251

Armstrong, S., and P. Lees. 2002. Effects of carprofen (R and S enantiomers and racemate) on the production of IL-1, IL-6 and TNF-alpha by equine chondrocytes and synoviocytes. J. Vet. Pharmacol. Ther. 25:145-153. doi:10.1046/j.13652885.2002.00397.x

Baldridge, S. L., J. F. Coetzee, S. S. Dritz, J. B. Reinbold, R. Gehring, J. Havel, and B. Kukanich. 2011. Pharmacokinetics and physiologic effects of intramuscularly administered xylazine hydrochloride-ketamine hydrochloride-butorphanol tartrate alone or in combination with orally administered sodium salicylate on biomarkers of pain in Holstein calves following castration and dehorning. Am. J. Vet. Res. 72:13051317. doi:10.2460/ajvr.72.10.1305

Basbaum, A. I., D. M. Bautista, G. Scherrer, and D. Julius. 2009. Cellular and molecular mechanisms of pain. Cell 139:267284. doi:10.1016/j.cell.2009.09.028 
Brentnall, C., Z. Cheng, Q. A. McKellar, and P. Lees. 2013. Influence of oxytetracycline on carprofen pharmacodynamics and pharmacokinetics in calves. J. Vet. Pharmacol. Ther. 36:320-328. doi:10.1111/jvp.12000

Coetzee, J. F. 2013a. A review of analgesic compounds that can be used in food animals in the United States. Vet. Clin. North Am. Food Anim. Pract. 29:11-28. doi:10.1016/j.cvfa.2012.11.008

Coetzee, J. F. 2013b. Assessment and management of pain associated with castration in cattle. Vet. Clin. North Am. Food Anim. Pract. 29(1):75-101. doi:10.1016/j.cvfa.2012.11.002

Coetzee, J. F., R. A. Mosher, B. KuKanich, R. Gehring, B. Robert, J. B. Reinbold, and B. J. White. 2012. Pharmacokinetics and effect of intravenous meloxicam in weaned Holstein calves following scoop dehorning without local anesthesia. BMC Vet. Res. 8:153. doi:10.1186/1746-6148-8-153

Delatour, P., R. Foot, A. P. Foster, D. Baggot, and P. Lees. 1996. Pharmacodynamics and chiral pharmacokinetics of carprofen in calves. Br. Vet. J. 152:183-198. doi:10.1016/S00071935(96)80073-X

Donalisio, C., R. Barbero, B. Cuniberti, C. Vercelli, M. Casalone, and G. Re. 2013. Effects of flunixin meglumine and ketoprofen on mediator production in ex vivo and in vitro models of inflammation in healthy dairy cows. J. Vet. Pharmacol. Ther. 36:130-139. doi:10.1111/j.1365-2885.2012.01396.x

Faulkner, P. M., and D. M. Weary. 2000. Reducing pain after dehorning in dairy calves. J. Dairy Sci. 83:2037-2041. doi:10.3168/jds.S0022-0302(00)75084-3

Fillingim, R. B., C. D. King, M. C. Ribeiro-Dasilva, B. RahimWilliams, and J. L. Riley III. 2009. Sex, gender, and pain: A review of recent clinical and experimental findings. J. Pain 10:447-485. doi:10.1016/j.jpain.2008.12.001

Fraccaro, E., J. F. Coetzee, R. Odore, L. N. Edwards-Callaway, B. Kukanich, P. Badino, L. Bertolotti, H. Glynn, J. Dockweiler, K. Allen, and L. Bergamasco. 2013. A study to compare circulating flunixin, meloxicam and gabapentin concentrations with prostaglandin E2 levels in calves undergoing dehorning. Res. Vet. Sci. 95:204-211. doi:10.1016/j.rvsc.2013.01.018

Glynn, H. D., J. F. Coetzee, L. N. Edwards-Callaway, J. C. Dockweiler, K. A. Allen, B. Lubbers, M. Jones, E. Fraccaro, L. L. Bergamasco, and B. KuKanich. 2013. The pharmacokinetics and effects of meloxicam, gabapentin, and flunixin in postweaning dairy calves following dehorning with local anesthesia. J. Vet. Pharmacol. Ther. 36:550-561. doi:10.1111/ jvp. 12042

Heinrich, A., T. F. Duffield, K. D. Lissemore, and S. T. Millman. 2010. The effect of meloxicam on behavior and pain sensitivity of dairy calves following cautery dehorning with a local anesthetic. J. Dairy Sci. 93:2450-2457. doi:10.3168/ jds.2009-2813

Heinrich, A., T. F. Duffield, K. D. Lissemore, E. J. Squires, and S. T. Millman. 2009. The impact of meloxicam on postsurgical stress associated with cautery dehorning. J. Dairy Sci. 92:540-547. doi:10.3168/jds.2008-1424

Huber, J., T. Arnholdt, E. Möstl, C. C. Gelfert, and M. Drillich. 2013. Pain management with flunixin meglumine at dehorning of calves. J. Dairy Sci. 96:132-140. doi:10.3168/ jds.2012-5483

Huntjens, D. R. H., M. Danhof, and O. E. Della Pasqua. 2005. Pharmacokinetic-pharmacodynamic correlations and biomarkers in the development of COX-2 inhibitors. Rheumatology 44:846-859. doi:10.1093/rheumatology/ keh627
Lees, P., P. Delatour, A. P. Foster, R. Foot, and D. Baggot. 1996. Evaluation of carprofen in calves using a tissue cage model of inflammation. Br. Vet. J. 152:199-211. doi:10.1016/S00071935(96)80074-1

Lees, P., M. F. Landoni, J. Giraudel, and P. L. Toutain. 2004. Pharmacodynamics and pharmacokinetics of nonsteroidal anti-inflammatory drugs in species of veterinary interest. J. Vet. Pharmacol. Ther. 27:479-490. doi:10.1111/j.13652885.2004.00617.x

Levoin, N., C. Blondeau, C. Guillaume, L. Grandcolas, F. Chretien, J. Y. Jouzeau, E. Benoit, Y. Chapleur, P. Netter, and F. Lapicque. 2004. Elucidation of the mechanism of inhibition of cyclooxygenases by acyl-coenzyme A and acylglucuronic conjugates of ketoprofen. Biochem. Pharmacol. 68:1957-1969. doi:10.1016/j.bcp.2004.07.015

McMeekan, C. M., K. J. Stafford, D. J. Mellor, R. A. Bruce, R. N. Ward, and N. G. Gregory. 1998. Effects of regional analgesia and/or a non-steroidal anti-inflammatory analgesic on the acute cortisol response to dehorning in calves. Res. Vet. Sci. 64:147-150. doi:10.1016/S0034-5288(98)90010-8

Miciletta, M., B. Cuniberti, R. Barbero, and G. Re. 2014. In vitro enantioselective pharmacodynamics of Carprofen and Flunixin-meglumine in feedlot cattle. J. Vet. Pharmacol. Ther. 37:43-52. doi:10.1111/jvp.12052

Nazarian, A., J. M. Tenayuca, F. Almasarweh, A. Armendariz, and D. Are. 2014. Sex differences in formalin-evoked primary afferent release of substance P. Eur. J. Pain 18:39-46. doi:10.1002/j.1532-2149.2013.00346.x

Pang, W. Y., B. Earley, T. Sweeney, and M. A. Crowe. 2006. Effect of carprofen administration during banding or burdizzo castration of bulls on plasma cortisol, in vitro interferon-gamma production, acute-phase proteins, feed intake, and growth. J. Anim. Sci. 84:351-359.

Stafford, K. J., and D. J. Mellor. 2005. Dehorning and disbudding distress and its alleviation in calves. Vet. J. 169:337-349. doi:10.1016/j.tvj1.2004.02.005

Stafford, K. J., and D. J. Mellor. 2011. Addressing the pain associated with disbudding and dehorning in cattle. Appl. Anim. Behav. Sci. 135:226-231. doi:10.1016/j.applanim.2011.10.018

Stewart, M., K. J. Stafford, S. K. Dowling, A. L. Schaefer, and J. R. Wester. 2008. Eye temperature and heart rate variability of calves disbudded with or without local anesthetic. Physiol. Behav. 93:789-797. doi:10.1016/j.physbeh.2007.11.044

Stewart, M., J. M. Stookey, K. J. Stafford, C. B. Tucker, A. R. Rogers, S. K. Dowling, G. A. Verkerk, A. L. Schaefer, and J. R. Webster. 2009. Effects of local anesthetic and a nonsteroidal antiinflammatory drug on pain responses of dairy calves to hot-iron dehorning. J. Dairy Sci. 92:1512-1519. doi: $10.3168 /$ jds.2008-1578

Stilwell, G., R. C. Carvalho, N. Carolino, M. S. Lima, and D. M. Broom. 2010. Effect of hot-iron disbudding on behaviour and plasma cortisol of calves sedated with xylazine. Res. Vet. Sci. 88:188-193. doi:10.1016/j.rvsc.2009.06.012

Stilwell, G., M. S. Lima, and D. M. Broom. 2008a. Comparing plasma cortisol and behaviour of calves dehorned with caustic paste after non-steroidal-anti-inflammatory analgesia. Livest. Sci. 119:63-69. doi:10.1016/j.livsci.2008.02.013

Stilwell, G., M. S. Lima, and D. M. Broom. 2008b. Effects of nonsteroidal anti-inflammatory drugs on long-term pain in calves castrated by use of an external clamping technique following epidural anesthesia. Am. J. Vet. Res. 69:744-750. doi:10.2460/ajvr.69.6.744 
Stilwell, G., M. S. Lima, R. C. Carvalho, and D. M. Broom. 2012. Effects of hot-iron disbudding using regional anesthesia with and without carprofen, on cortisol and behavior of calves. Res. Vet. Sci. 92:338-341. doi:10.1016/j.rvsc.2011.02.005

Stock, M. L., S. L. Baldridge, D. D. Griffin, and J. F. Coetzee. 2013. Bovine dehorning: Assessing pain and providing analgesic management. Vet. Clin. North Am. Food Anim. Pract. 29:103-133. doi:10.1016/j.cvfa.2012.11.001

Stock, M. L., S. T. Millman, L. A. Barth, N. K. Van Engen, W. H. Hsu, C. Wang, R. Gehring, R. L. Parsons, and J. F. Coetzee. 2015. The effects of firocoxib on cautery disbudding pain and stress responses in preweaned dairy calves. J. Dairy Sci. 98:6058-6069. doi:10.3168/jds.2014-8877

Summer, G. J., O. A. Dina, and J. D. Levine. 2007. Enhanced inflammatory hyperalgesia after recovery from burn injury. Burns 33:1021-1026. doi:10.1016/j.burns.2007.02.007
Summer, G. J., E. A. Romero-Sandoval, O. Bogen, O. A. Dina S. G. Khasar, and J. D. Levine. 2008. Proinflammatory cytokines mediating burn-injury pain. Pain 135:98-107. doi:10.1016/j.pain.2007.05.012

Tapper, K. R., J. P. Goff, B. L. Leuschen, J. K. West, and S. T. Millman. 2011. Novel techniques for anesthesia during disbudding of calves. J. Anim. Sci. 89(E-Suppl.):413 (Abstr.).

U.S. Food and Drug Administration (FDA). 1994. Animal medicinal drug use clarification act of 1994 (AMDUCA). http://www.fda.gov/AnimalVeterinary/ GuidanceComplianceEnforcement/ActsRulesRegulations/ ucm085377.htm. (Accessed April 1, 2015.)

Van Engen, N. K., M. L. Stock, T. Engelken, R. C. Vann, L. W. Wulf, L. A. Karriker, W. D. Busby, J. Lakritz, A. J. Carpenter, B. J. Bradford, W. H. Hsu, C. Wang, and J. F. Coetzee 2014. Impact of oral meloxicam on circulating physiological biomarkers of stress and inflammation in beef steers after long-distance transportation. J. Anim. Sci. 92:498-510. doi:10.2527/jas.2013-6857 